\title{
Topography of Primary Molar Pulp Chamber Floor: A Scanning Electron Microscopy and Micro-Computed Tomography Analysis
}

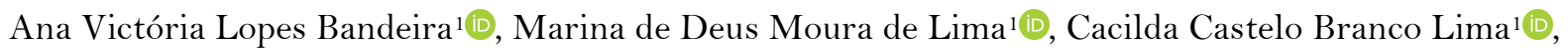
Marcoeli Silva de Moura1® ${ }^{\circledR}$, Altair Antoninha Del Bel Cury²@, Lucia de Fátima Almeida de Deus

Moura1(10)

${ }^{1}$ Department of Pathology and Dentistry Clinic, School of Dentistry, Federal University of Piauí, Teresina, PI, Brazil.

${ }^{2}$ Department of Prosthodontics and Periodontology, Piracicaba Dental School, University of Campinas, Piracicaba, SP, Brazil.

Correspondence: Lucia de Fátima Almeida de Deus Moura, Campus Universitário Ministro Petrônio Portella - Bloco 5 Programa de Pós-Graduação em Odontologia, Bairro Ininga, Teresina, Piauí, Brazil. 64049-550. E-mail: mouraiso@uol.com.br

Academic Editor: Alessandro Leite Cavalcanti

Received: 08 February 2021 / Review: 07 May 2021 / Accepted: 14 June 2021

How to cite: Bandeira AVL, Lima MDM, Lima CCB, Moura MS, Cury AADB, Moura LFAD. Topography of primary molar pulp chamber floor: a scanning electron microscopy and micro-computed tomography analysis. Pesqui Bras Odontopediatria Clín Integr. 2021; 21 :e0033. https://doi.org/10.1590/pboci.2021.150

\begin{abstract}
Objective: To determine in vitro the frequency, shape, type, diameter, and patency of accessory canals in the primary molars pulp chamber floor. Material and Methods: Sixteen healthy primary molars were evaluated by micro-computed tomography and scanning electron microscopy. Descriptive analyses of the frequency, shape (round, oval, or irregular), type (blind, true, or hidden), patency and diameter of the accessory canals were performed. Results: Half of the teeth presented accessory canals, $62.5 \%$ of which were located in the upper molars and $37.5 \%$ in the lower molars. The most frequent shape was irregular. In three-dimensional analysis, blind accessory canals (12.5\%) and with patency $(18.7 \%)$ of the teeth were observed. The average accessory canal diameter was $51.97 \mu \mathrm{m}( \pm 26.03 \mu \mathrm{m})$. Conclusion: Upper molars showed a higher frequency of accessory canals with larger diameters. The irregular shape was the most frequent. $18.7 \%$ of accessory channels showed patency.
\end{abstract}

Keywords: Dental Pulp Cavity; Tomography, X-Ray Computed; Molar; Microscopy, Electron, Scanning. 


\section{Introduction}

The pulp chamber floor of deciduous molars presents peculiarities such as reduced dentin thickness, resorption areas, and the presence of accessory canals [1]. These conditions favor communications of the coronal pulp region with the periodontal region, which is where the successor's tooth is under development $[2,3]$.

Pulpo-periodontal communications enable diffusion of bacterial metabolism products [4] and substances used in pulp therapies to the periodontal region [5]. In addition, the communication routes can explain the presence of radiolucent areas in the root regions of deciduous molars with infected pulp [6].

Accessory canals are the result of failures in the formation of the Hertwig epithelial sheath during the root formation [7]. These failures are caused by modifications in the odontoblast differentiation phase associated with discontinuation of dentin formation, giving rise to small spaces [8]. In vital teeth, the spaces are filled by connective tissue and blood vessels and allow physiological pulpoperiodontal communications $[9,10]$. In teeth with pulp necrosis, these tissues are replaced by the bacteria and endotoxins of the root canal system microbiome, and these are virulence factors involved in inflammatory reactions in the periapical and periradicular tissues [11-13].

An associated clinical complication of pulpal infection in the floor region of the pulp of deciduous molars is damage to the ameloblasts of premolars in development, increasing the chances of developing defects in the tooth enamel $[5,11,14,15]$. Such defects are frequent causes of aesthetic complaints, dentin sensitivity and retention factors of dental biofilm [16].

There is a gap in the literature that addresses the topography of the pulp chamber floor of primary molars, and it is believed that in the region, there is permeability related to several factors, among them the presence of accessory channels $[17,18]$. From this perspective, the aim of this in vitro study was to determine the frequency, shapes, diameters and communication with the periodontal tissues of accessory canals in the pulp chamber floor of deciduous molars.

\section{Material and Methods}

Sample Selection and Preparation

The study was approved by the Research Ethics Committee (Opinion number 2,100,116) and followed the ethical principles of the Declaration of Helsinki.

Primary molars used in the study were extracted when the permanent successor had a root formation of $2 / 3$ or more and the children were aged nine to 11 years. The sample was consecutive and consisted of healthy human primary molars from children of both sexes who were patients of the children's dental clinic.

The samples were taken between August 2017 and November 2017, regardless to ethnicity or socioeconomic status. Molars, which presented integrity in furcation region, were included in the study. Sixteen primary molars were used in this study: four upper first molars, four lower first molars, four upper second molars and four lower second molars. After extraction, the teeth were kept in saline solution $(\mathrm{NaCl}$ $0.9 \%)$ until analysis.

The characterization of the accessory canals in the molar pulp chamber floor was determined according to the classification of Paras et al. [19] and Sharma et al. [20]. The evaluation of the frequency, shape (round, oval, or irregular) and diameter of the canals was performed by scanning electron microscopy (SEM). To determine the type (blind, true, hidden) and communication with the periodontal tissues of the 
accessory canals, micro-computed tomography (micro-CT) was used. Both evaluations were carried out for each tooth.

Analysis by Scanning Electron Microscopy (SEM)

After the analysis using micro-CT, the molars were sectioned at a thickness of two mm above the amelocemental junction and two mm apical to the floor of the pulp chamber.20 The cuts were made with a high-concentration diamond wafering blade (4" x $0.12 "$ × 0.5 " Lapmaster) coupled to a precision cutter Isomet 1000 (Isomet, Buehler Ltd., Lake Bluff, IL, USA).

After sectioning, the specimens were immersed in a 3\% sodium hypochlorite solution for 10 minutes to remove organic debris [20]. They were then put into individual pots with distilled water in ultrasonic tanks for five minutes to complement the removal of pulp remnants [1,2]. Next, they were dehydrated by increasing $70 \%, 95 \%$, and $100 \%$ ethyl alcohol concentrations, with four exchanges every 15 minutes. The specimens were then arranged in a desiccator (Marconi MA 410/CF), at room temperature, for 24 $\mathrm{h}$ [20].

The specimens were mounted on stubs using double-sided carbon tape and placed in the vacuum chamber of a gold coating unit (Bal-tec SCD 050 Sputter Coater). After, they were submitted to SEM analysis (JEOL - JSM 5600 PV scanning microscope, Tokyo, Japan), with magnifications from $18 \mathrm{X}$ to $400 \mathrm{X}$. The frequency and diameter of the accessory canals were recorded.

\section{Analysis by Micro-CT}

The teeth were dried with gauze compresses and scanned in the Skyscan 1174 apparatus (Bruker, Kontich, Belgium) using $50 \mathrm{kV}, 800 \mathrm{~mA}, 0.8$ step rotation, $360^{\circ}$ rotation around the vertical axis, voxel size of $11.9 \mu \mathrm{m}$ and matrix of $1304 \times 1024$ pixels. The image of each specimen was reconstructed, containing the area of the furcation region pulp chamber floor of molars, using the software NRecon (Bruker, Kontich, Belgium). For viewing of the data on coronal, transaxial and sagittal sections of the region of furcation, the software DataViewer (Bruker, Kontich, Belgium) was used.

To determine the type and communication with the periodontal tissues of the accessory canals at the floor of the pulp, designs in three dimensions $(3 \mathrm{D})$ were constructed by binarization of the dentin and root canal system, using the software CTAn and CTVol (Bruker, Kontich, Belgium). The images were evaluated by two experienced and calibrated operators with experience in the analysis of the root and root canal morphologies obtained using micro-CT technology. A double-blind evaluation was performed and a third evaluator in cases of disagreement.

\section{Data Analysis}

The data were recorded in an elaborate form then tabulated and analyzed using the software Statistical Package for the Social Sciences (SPSS ${ }^{\circledR}$ Statistics for Windows, version 22.0, IBM Corp., Armonk, NY, USA). Descriptive analyses of the quantity, shape and diameter of the accessory canals were performed. To analyze the diameter difference between the upper and lower molar canals, the Mann-Whitney test was used since the data did not have a normal distribution according to the Shapiro-Wilk test. A p-value $<0.05$ was considered statistically significant.

\section{Results}


The SEM micrographs of the deciduous molars revealed accessory canals on half of selected teeth. Most of these were located in the upper molars (Table 1). The shape of the founded accessory canals is presented in Figure 1. The irregular form was the most frequent accessory canal shape, with $63.6 \%$ in the upper molars and $50 \%$ in the lower molars (Table 2). There was no difference in the means of accessory canal diameters between the upper and lower molars $(\mathrm{p}=0.083)$ (Table 3$)$.

The micro-CT analysis revealed permeability in the furcation region without the involvement of the pulp chamber floor in two specimens corresponding to lower first and second molars. Communication with the periodontal tissues was observed in three specimens. A first molar had an accessory canal connecting the floor of the pulp chamber to the palatine canal and accessory canals true type, connecting the floor of the pulp with the furcation region on two maxillary molars. Blind accessory canals were detected on the floor of the pulp chamber of two upper molars. In the four upper second molars, intercanal communications were found (Figure 2).

Table 1. Descriptive analysis of deciduous molar accessory canals.

\begin{tabular}{|c|c|c|c|c|c|c|c|}
\hline \multirow[b]{2}{*}{ Primary Molar } & \multirow[b]{2}{*}{ Number of Teeth } & \multicolumn{2}{|c|}{ Accessory Canals } & \multicolumn{4}{|c|}{ Frequency of Accessory Canals } \\
\hline & & $\begin{array}{c}\text { Presence } \\
\mathrm{N}(\%)\end{array}$ & $\begin{array}{c}\text { Absence } \\
\mathrm{N}(\%)\end{array}$ & $\mathrm{N}$ & Min. & Max. & Mean $( \pm$ SD $)$ \\
\hline Upper & 8 & $5(62.5)$ & $3(37.5)$ & 11 & $\mathrm{O}$ & 4 & $1.38( \pm 1.51)$ \\
\hline Lower & 8 & $3(37.5)$ & $5(62.5)$ & 8 & $\mathrm{O}$ & 4 & $1.00( \pm 1.60)$ \\
\hline
\end{tabular}

SD: Standard-Deviation; N: Number Of Accessory Canals; Min: Minimum; Max: Maximum.

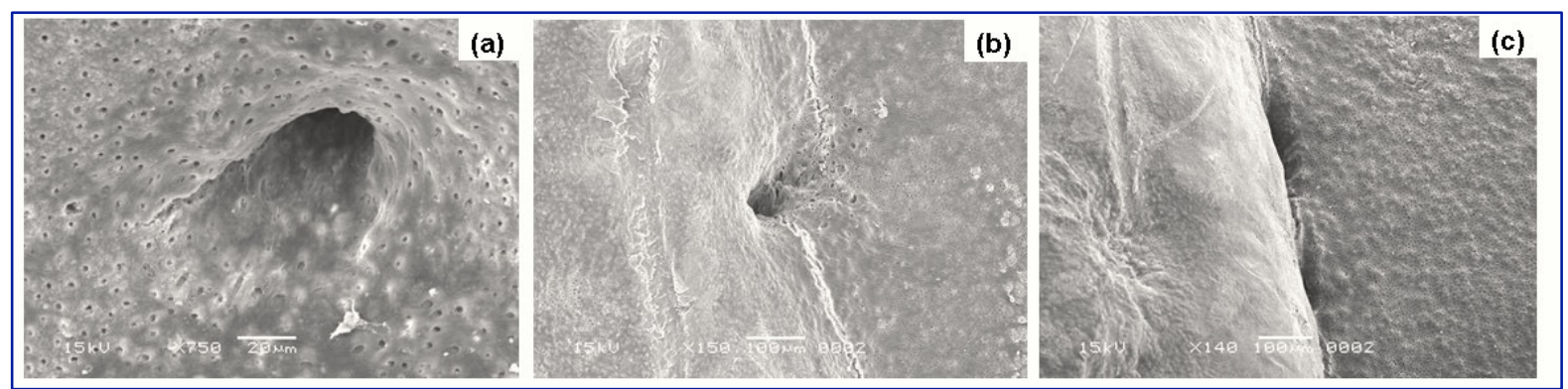

Figure 1. Scanning electron micrograph of accessory canals. Primary molars: (a) oval accessory canal (750X); (b) round accessory canal (150X); (c) irregular accessory canal (140X).

Table 2. Classification of accessory canals by shape.

\begin{tabular}{|c|c|c|c|c|}
\hline \multirow[b]{2}{*}{ Primary Molar } & \multicolumn{3}{|c|}{ Accessory Canals Shape } & \multirow{2}{*}{$\begin{array}{l}\text { Total } \\
\mathrm{N}(\%)\end{array}$} \\
\hline & $\begin{array}{l}\text { Round } \\
\mathrm{N}(\%)\end{array}$ & $\begin{array}{c}\text { Oval } \\
\mathrm{N}(\%)\end{array}$ & $\begin{array}{c}\text { Irregular } \\
\mathrm{N}(\%)\end{array}$ & \\
\hline Upper & $2(18.2)$ & $2(18.2)$ & $7(63.6)$ & $11(100.0)$ \\
\hline Lower & $4(50.0)$ & $\mathrm{o}(0.0)$ & $4(50.0)$ & $8(100.0)$ \\
\hline
\end{tabular}

Table 3. Mean and standard deviation (SD) of diameter $(\mu \mathrm{m})$ of accessory canals and association between arches.

\begin{tabular}{ccccc}
\hline Primary Molar & Mean $( \pm \mathrm{SD})$ & $\begin{array}{c}\text { Diameter }(\boldsymbol{\mu m}) \\
\text { Minimum }\end{array}$ & Maximum & p-value* $^{*}$ \\
\hline Upper & $60.29( \pm 22.75)$ & 27.6 & 95.0 & 0.083 \\
Lower & $38.33( \pm 27.10)$ & 9.2 & 75.9 & \\
\hline
\end{tabular}

SD: Standard Deviation; * Mann-Whitney test. 


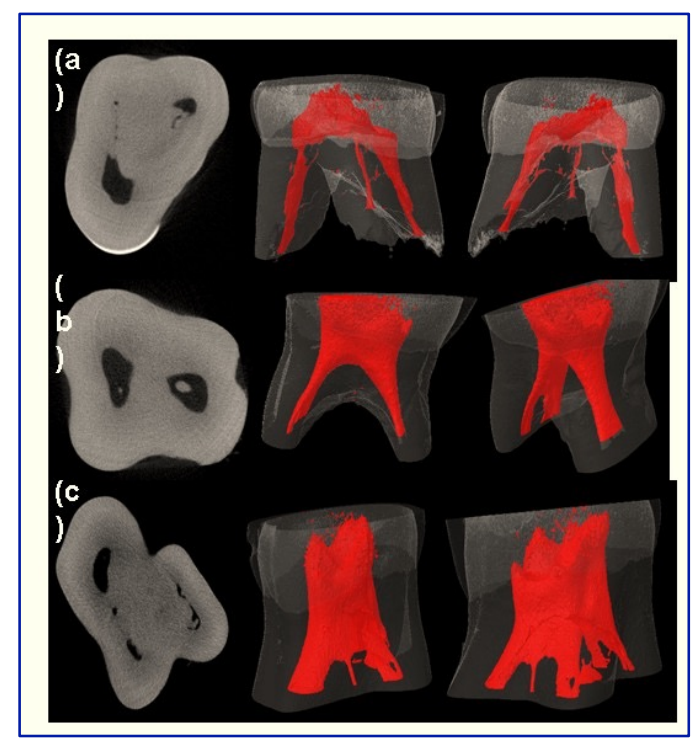

Figure 2. Axial micro-CT sections and 3D reconstructions of deciduous molars: (a) first molar with types blind and true accessory canals; (b) lower first molar without the presence of an accessory canal; (c) upper second molar with blind-type accessory canal and chamber canal.

\section{Discussion}

Different techniques have been used to determine the presence of accessory canals in the pulp chamber floor of molars, especially perfusion with ink [21], infusion of latex [19], lasers [15], digital radiographs, serial histological sections [7,10], scanning electron microscopy (SEM) [1,2,22], cone beam computed tomography [23] and micro-computed tomography (micro-CT) [24]. Analysis with micro-CT in addition to SEM enables optimal evaluation of the floor of the pulp of deciduous molars [22,25].

In the present study, half of the molars had accessory channels. However, only $18.7 \%$ had pulpoperiodontal communications; that is, they had patency. Through the three-dimensional analysis, it was also possible to observe blind-type canals. Blind-type canals are those that begin and end within the dentin $[19,26]$. These canals may acquire communication with the periodontal tissues when resorption progression occurs in the external furcation regions of the deciduous primary molars with necrotic pulps [11].

Concerning the shape of the accessory canals, irregular canal shape was the most frequent, and this result was discordant with the results of Sharma et al. [20], in which an oval shape was predominant. Further studies should be performed to assess whether there is a relationship between accessory canals and communication with the periodontal tissues of the pulp floor of deciduous molars.

In canals with large diameter, there may be an increased risk of dentin permeability with consequent diffusion of chemicals, biologicals, endotoxins or substances used in endodontic therapies for the periodontal spaces $[5,12,22,27]$. The clinical importance of this finding may be related to the presence of radiolucent images in the interradicular regions of the deciduous molars with pulp infections [6].

The presence of accessory canals was more frequent in maxillary molars; however, there was no statistically significant difference but suggesting that these teeth have a higher communication with the periodontal tissues in the furcation region when compared to the lower molars [2]. However, the presence of accessory canals is not the only factor influencing the communication with the periodontal tissues of the molar furcation region; dentin thickness and root resorption areas should also be considered [1]. Therefore, further studies should be performed to evaluate the thickness of dentin and the different degrees of resorption in the furcation region of molars with necrotic pulp. 
Failures in endodontic treatments are related to the presence of residual microorganisms in the root canal system in the furcation and periapical regions [27,28]. Accessory canals of molars with pulp necrosis become a favorable environment for bacterial housing and proliferation [29], which may spread to the periodontal region, where the premolars are in development $[5,7]$.

The study has a sample size limitation that can be justified because it is a consecutive sample that should meet the eligibility criteria; however, other studies should be done using a more significant sample size and that can be inferred for the population. Thus, the degree of applicability or generalization of the results needs to be analyzed with caution. In addition, it has also been pointed out that age, sex and ethnicity influence tooth morphology [18]. Another limitation is related to the MicroCT method that some anatomical features should not be visible because they are smaller than the pixel size in micrometers.

\section{Conclusion}

Upper molars showed a higher frequency of accessory canals with larger diameters. The irregular shape was the most frequent. A total of $18.7 \%$ of accessory channels showed patency.

\section{Authors' Contributions}

\begin{tabular}{|c|c|c|}
\hline AVLB (i) & https://orcid.org/0000-0003-2833-7425 & $\begin{array}{l}\text { Conceptualization, Methodology, Formal Analysis, Investigation, Resources and Writing - } \\
\text { Original Draft. }\end{array}$ \\
\hline MDML & https://orcid.org/0000-0002-7641-6331 & Methodology, Formal Analysis and Writing - Review and Editing. \\
\hline CCBL & https://orcid.org/0000-0002-2977-6035 & Methodology, Formal Analysis and Writing - Review and Editing. \\
\hline MSM & https://orcid.org/0000-0002-9044-9025 & Methodology, Formal Analysis and Writing - Review and Editing. \\
\hline $\mathrm{AABC}$ (iD) & https://orcid.org/0000-0002-4329-0437 & Methodology, Formal Analysis and Writing - Review and Editing. \\
\hline LFDM (iD) & https://orcid.org/0000-0002-4112-1533 & $\begin{array}{l}\text { Conceptualization, Methodology, Formal Analysis, Writing - Original Draft, Writing - Review } \\
\text { and Editing, Supervision and Project Administration. }\end{array}$ \\
\hline
\end{tabular}

\section{Financial Support}

This study was supported by the National Program for Academic Cooperation (PROCAD / CAPES) with number 071/2013.

\section{Conflict of Interest}

The authors declare no conflicts of interest.

\section{Data Availability}

The data used to support the findings of this study can be made available upon request to the corresponding author.

\section{Acknowledgements}

The experiment was carried out at Piracicaba School of Dentistry (FOP) - UNICAMP, in partnership with the FOP Centre for Microscopy and Images and Microbiology Laboratory.

\section{References}

[1] Kramer PF, Faraco IM, Meira R. A SEM investigation of accessory foramina in the furcation areas of primary molars. J Clin Pediatr Dent 2003, 27(2):157-62. https://doi.org/10.17796/jcpd.27.2.98132n48870n3303

[2] Kumar VD. A scanning electron microscope study of prevalence of accessory canals on the pulpal floor of deciduous molars. J Indian Soc Pedod Prev Dent 2009; 7(2):85-9. https://doi.org/10.4103/0970-4388.55332

[3] Lugliè PF, Grabesu V, Spano G, Lumbau A. Accessory foramina in the furcation area of primary molars. A SEM investigation. Eur J Paediatr Dent 2012; 13(4):329-32.

[4] Al-Fouzan KS. A new classification of endodontic-periodontal lesions. Int J Dent 2014; $2014: 919173$. https://doi.org/10.1155/2014/919173

[5] Cordeiro MMR, Rocha MJC. The effects of perirradicular inflamation and infection on a primary tooth and permanente successor. J Clin Pediatr Dent 2005; 29(3):193-200. https://doi.org/10.17796/jcpd.29.3.5238p10v21r2j162 
[6] Cleghorn BM, Boorberg NB, Christie WH. Primary human teeth and their root canal systems. Endod Topics 2012; 23(1):6-33. https://doi.org/10.1111/etp.12000

[7] Poornima P, Subba Reddy VV. Comparison of digital radiography, decalcification, and histologic sectioning in the detection of accessory canals in furcation areas of human primary molars. J Indian Soc Pedod Prev Dent 2008; 26(2):49-52. https://doi.org/10.4103/0970-4388.41615

[8] Gutmann JL. Prevalence, location, and patency of accessory canals in the furcation region of permanent molars. J Periodontol 1978; 49(1):21-6. https://doi.org/10.1902/jop.1978.49.1.21

[9] Kuroiwa M, Kodaka T, Abe M, Higashi S. Three-dimensional observations of accessory canals in mature and developing rat molar teeth. Acta Anat 1992; 144(3):284. https://doi.org/10.1159/000147239

[10] Zuza EP, Toledo BEC, Hetem S, Spolidório LC, Mendes AJ, Rosetti EP. Prevalence of different types of accessory canals in the furcation area of third molars. J Periodontal 2006; 77(10):1755-61. https://doi.org/10.1902/jop.2006.060112

[11] Bolan M, Rocha MJC. Histopathologic study of physiological and pathological resorptions in human primary teeth. Oral Surg Oral Med Oral Pathol Oral Radio Endod 2007; 104(5):680-5. https://doi.org/10.1016/j.tripleo.2006.11.047

[12] Queiroz AM, Arid J, Nelson-Filho P, Lucisano MP, Silva RAB, Sorgi CA, et al. Correlation between bacterial endotoxin levels in root canals of primary teeth and the periapical lesion area. J Dent Child 2016; 83(1):9-15.

[13] Neelakantan P, Herrera DR, Pecorari VGA, Gomes BPFA. Endotoxin levels after chemomechanical preparation of root canals with sodium hypochlorite or chlorhexidine: a systematic review of clinical trials and meta-analysis. Int Endod J 2019; 52(1):19-27. https://doi.org/10.1111/iej.12963

[14] Kalra N, Sushma K, Mahapatra GK. Changes in developing succedaneous teeth as a consequence of infected deciduous molars. J Indian Soc Pedod Prev Dent 2000; 18(3):90-4.

[15] Guglielmi CA, Müller-Ramalho K, Scaramucci T, da Silva SR, Imparato JC, Pinheiro SL. Evaluation of the furcation area permeability of deciduous molars treated by neodymium:yttrium-aluminum-garnet laser or adhesive. Lasers Med Sci 2010; 25(6):873-80. https://doi.org/10.1007/s10103-009-0730-Z

[16] Vargas-Ferreira F, Salas MMS, Nascimento GG, Tarquinio SBC, Jr Faggion CM, Peres MA, et al. Association between developmental defects of enamel and dental caries: A systematic review and meta-analysis. J Dent 2015; 43(6):619-28. https://doi.org/10.1016/j.jdent.2015.03.011

[17] Sidow SJ, West LA, Liewehr FR, Loushine RJ. Root canal morphology of human maxillary and mandibular third molars. J Endod 2000; 26(11):675-8. https://doi.org/10.1097/00004770-200011000-00011

[18] Zhang W, Tang Y, Liu C, Shen Y, Feng X, Gu Y. Root and root canal variations of the human maxillary and mandibular molars in a Chinese population: A micro-computed tomographic study. Arch Oral Bio 2018; 95:134-40. https://doi.org/10.1016/j.archoralbio.2018.07.020

[19] Paras LG, Rapp R, Piesco NP, Zeichner SJ, Zullo TG. An investigation of accessory foramina in furcation areas of primary molars: Part 1 - SEM observations of frequency, size and location of accessory foramina in the internal and external furcation areas. J Clin Pediatr Dent 1993; 17(2):65-9.

[20] Sharma U, Gulati A, Gill N. An investigation of accessory canals in primary molars - an analytical study. Int J Paediatr Dent 2016; 26(2):149-56. https://doi.org/10.1111/ipd.12178

[21] Niemann RW, Dickinson GL, Jackson CR, Wearden S, Skidmore AE. Dye ingress in molars: furcation to chamber floor. J Endod 1993; 19(6):293-6. https://doi.org/10.1016/s0099-2399(06)80459-0

[22] Dammaschke T, Witt M, Ott K, Schafer E. Scanning electron microscopic investigation of incidence, location, and size of accessory foramina in primary and permanent molars. Quintessence Int 2004; 35(9):699-705.

[23] Ozcan G, Sekerci AE, Cantekin K, Aydinbelge M, Dogan S. Evaluation of root canal morphology of human primary molars by using CBCT and comprehensive review of the literature. Acta Odontol Scand 2016; 74(4):250-8. https://doi.org/10.3109/00016357.2015.1104721

[24] Acar B, Kamburoglu K, Tatar I, Arikan V, Çelik HH, Yuksel S, et al. Comparison of micro-computerized tomography and cone-beam computerized tomography in the detection of accessory canals in primary molars. Imaging Sci Dent 2015; 45(4):205-11. https://doi.org/10.5624/isd.2015.45.4.205

[25] Verma P, Love RM. A micro CT study of the mesiobuccal root canal morphology of the maxillary first molar tooth. Int Endod J 2011; 44(3):210-7. https://doi.org/10.1111/j.1365-2591.2010.01800.x

[26] Ahmed HMA, Dummer PMH. A new system for classifying tooth, root and canal anomalies. Int Endod J 2018; 51(4):389-404. https://doi.org/10.1111/iej.12867

[27] Tannure PN, Barcelos R, Portela MB, Gleiser R, Primo LG. Histopathologic and SEM analysis of primary teeth with pulpectomy failure. Oral Surg Oral Med Oral Pathol Oral Radiol Endod 2009; 108(1):e29-e33. https://doi.org/10.1016/j.tripleo.2009.03.014

[28] Rocha CT, Rossi MA, Leonardo MR, Rocha LB, Nelson-Filho P, Silva LA. Biofilm on the apical region of roots in primary teeth with vital and necrotic pulps with or without radiographically evident apical pathosis. Int Endod J 2008, 41(8):664-9. https://doi.org/10.1111/j.1365-2591.2008.01411.x

[29] Nair PN. On the causes of persistent apical periodontitis: a review. Int Endod J 2006; 39(4):249-81. https://doi.org/10.1111/j.1365-2591.2006.01099.x 